\title{
Parametric equations for Shields parameter and wave orbital velocity in combined current and irregular waves
}

\author{
A. Roulund \\ DONG Energy A/S, Nesa Allé 1, 2820 Gentofte, Denmark
}

J. Sutherland \& D. Todd

HR Wallingford Limited, Howbery Park, Wallingford, Oxfordshire, OX10 8BA, United Kingdom

J. Sterner

COWI A/S, Parallelvej 2, 2800 Kongens Lyngby, Denmark

\begin{abstract}
A fundamental requirement for any scour assessment and scour protection design is the ability to determine the Shields parameter for combined wave and current conditions.

The Shields parameter can be calculated for current combined with monochromatic waves using the approach of Soulsby (1997) in combination with the wave friction factor concept. For current in combination with irregular waves, the same approach is suggested using a wave orbital velocity, $U_{m}$, for representation of the irregular sea state. $U_{m}$ is defined as 1.41 times the standard deviation of the near bed wave orbital velocity.

The Soulsby (2006) expression for $U_{m}$ is compared with a hyperbolic expression and validated using numerical methods and laboratory measurements.

A large number of expressions exist for the wave friction factor as a function of relative bed roughness. From a literature study, the paper proposes a combination of existing expressions to cover relative bed roughnesses from sand over gravel to coarse armour rock.
\end{abstract}

\section{INTRODUCTION}

The Shields parameter, $\theta$, is central within the field of sediment transport and scour studies. For a granular, non-cohesive material exposed to current and waves, the Shields parameter represents the ratio of the driving hydraulic loading to the stabilising gravitational force.

The granular material is represented by its mean diameter, $D_{50}$, and particle density, $\rho_{s}$.

The hydraulic loading can, for an irregular seastate in combination with current, be represented by the bed shear stress, $\tau_{\max }$, found by combining the current bed shear stress, $\tau_{c}$, and the wave bed shear stress from irregular waves, $\tau_{w}$. The Shields parameter is then given as:

$\theta=\frac{\tau_{\max }}{g\left(\rho_{s}-\rho_{w}\right) D_{50}}$

where $g$ is gravity and $\rho_{w}$ is water density.

While the importance of the Shields parameter is not questioned in the scientific or engineering community, it appears that consensus on its calculation from seastate parameters is not complete.

The present paper proposes a methodology for Shields parameter calculations for application within scour assessment and scour protection design. The methodology comprises: 1) Calculations of bed shear stress from currents only; 2) Calculation of near bed wave orbital velocity for an irregular seastate; 3) Determination of the wave friction factor and calculation of wave bed shear stress; and 4) Combinations of current and wave bed shear stresses for calculation of the Shields parameter.

Step 1), calculation of bed shear stress from currents only is easily achieved by using for instance a logarithmic velocity profile.

Steps 2) and 3) are more complex and are further discussed below.

Step 4), calculation of $\tau_{\max }$, is accomplished by combining the bed shear stress from currents only with the bed shear stress from waves according to the methodology of Soulsby (1997).

In expansion of Step 2), for irregular waves, a representative bed shear stress, $\tau_{w}$, can be calculated using the friction factor concept. This involves the selection of a representative near bed wave orbital velocity from the irregular seastate. Sumer and Fredsøe (2001) finds that $U_{m}$ provides the best representation of an irregular seastate in relation to scour development.

$U_{m}=\sqrt{2} \sigma_{U}$

where $\sigma_{U}$ is the standard deviation, or rms value, $U_{r m s}$, of the near bed wave orbital velocity. 
$U_{m}$ has been used in a number of studies of scour and scour protection stability to characterise the near bed wave orbital velocity of the irregular seastate in physical model tests. Some of the more recent studies comprise De Vos et al. (2012), Nielsen et al. (2015) and Petersen et al. (2015). In these papers, $U_{m}$ is obtained directly from measurements and time series analysis of the near bed velocity.

From an engineering perspective, it is valuable to have a parametric expression for $U_{m}$ based on readily available seastate parameters such as significant wave height, $H_{s}$, peak wave period, $T_{p}$, and water depth, $h$. These seastate parameters are typically available for design.

In Soulsby (1997) a graphical relation is given between $\sigma_{U}$ and the seastate parameters $H_{s}, T_{z}$ and $h$, where $T_{z}$ is the zero-crossing wave period. The relationship is based on time series analyses of numerically generated JONSWAP irregular wave trains. In Soulsby (2006) an exponential expression is provided to the graphical relation of $U_{m}$.

Wave orbital velocities decay hyperbolically towards the seabed. With this analogy, this paper considers a hyperbolic expression for $U_{m}$ as a possible alternative to the Soulsby (2006) exponential expression. The hyperbolic expression is compared with the Soulsby exponential expression and both expressions are validated using numerical methods and laboratory measurements.

Step 3): The wave friction factor concept has been developed for regular waves, whereby the maximum bed shear stress, $\tau_{o}$, under a wave can be calculated as:

$\tau_{o}=\frac{1}{2} \rho_{w} f_{w} U_{o}^{2}$

Where $f_{w}$ is the wave friction factor and $U_{o}$ is the maximum near bed wave orbital velocity.

The same friction factor concept, in which $U_{m}$ replaces $U_{o}$ for the calculation of $\tau_{w}$ in irregular waves, is suggested:

$\tau_{w}=\frac{1}{2} \rho_{w} f_{w} U_{m}^{2}$

It is noted that $U_{m}$ reduces to $U_{o}$ in the case of monochromatic linear waves Sumer and Fredsøe (2001). It is further noted that the bed shear stress, $\tau_{w}$, calculated using $U_{m}$, is not the maximum bed shear stress of the seastate, but solely a representative bed shear stress.

For a rough bed, the wave friction factor is a function of the wave stroke to grain size ratio, $A / k_{s}$. Several suggestions are presented in the literature for this functional relationship.

This paper presents a combination of existing expressions, providing a continuous formulation cover- ing relative bed roughness from sand over gravel to coarse armour rock.

An engineering example for calculations of the Shields parameter, near bed wave orbital velocity and friction factor for combined irregular waves and current is presented for illustration of the methodology.

\section{NUMERICAL CALCULATION OF NEAR BED WAVE ORBITAL VELOCITY}

Numerical calculation of $U_{m}$ has been performed for validation of the parametric expressions. In the numerical calculations, $U_{m}$ is derived from the standard deviation, $\sigma_{u(t)}$, taken from a 3 hour time series of bottom wave orbital velocities, $u(t)$, under an irregular seastate:

$U_{m}=\sqrt{2} \sigma_{u(t)}$

where

$u(t)=2 \pi \sum_{i}^{N} \frac{a_{i}}{T_{i}} \frac{1}{\sinh \left(k_{i} h\right)} \cos \left(\frac{2 \pi}{T_{i}} t\right)$

in which $t$ is time, $N$ is the number of wave components, $T_{i}$ is the wave period of wave component $i$ and $a_{i}$ is the amplitude of the wave component derived from the JONSWAP wave spectrum:

$a_{i}=\sqrt{2 \cdot \Delta f \cdot S_{J S}\left(f_{i}\right)}$

where $S_{J S}$ is the JONSWAP spectral energy at wave component frequency $f_{i}=1 / T_{i}$ and $\Delta f$ is the discrete frequency width $\Delta f=f_{i+1}-f_{i}$.

$N=1500$ wave components were applied for each irregular seastate calculation conducted.

The peakedness of the JONSWAP spectrum is governed by the peak enhancement factor, $\gamma_{\mathrm{JS}}$. The JONSWAP spectrum is defined within $\gamma_{\mathrm{JS}}=1$ to 5 . $\gamma_{\mathrm{JS}}=1$ corresponds the Pierson-Moskowitz spectrum for a fully developed seastate, while $\gamma_{\mathrm{JS}}=3$ is a typical North Sea value with more wave energy concentrated around the peak wave of the wave period. $\gamma_{\mathrm{JS}}$ $=5$ is the extreme limit for the JONSWAP spectrum.

From DNV OS-J101, a simple relation between significant wave height and peak wave period for a JONSWAP spectrum can be expressed as:

$T_{p}= \begin{cases}5.0 \sqrt{H_{s}} & \gamma_{J S}=1 \\ 4.0 \sqrt{H_{s}} & \gamma_{J S}=3 \\ 3.6 \sqrt{H_{S}} & \gamma_{J S}=5\end{cases}$

The numerical calculations of near bed wave orbital velocity have been performed with $\gamma_{\mathrm{JS}}=1,3$ and 5 . 


\section{EXPERIMENTAL SETUP FOR NEAR BED VELOCITY MEASUREMENTS}

Near bed velocity measurements have been analyzed for experimental determination of $U_{m}$ based on the standard deviation of the velocity signal (5). The measurements were conducted at HR Wallingford in the Fast Flow Facility (Whitehouse et al. 2014). Irregular JONSWAP wave conditions were generated using the HR Wallingford Merlin software. No current was superimposed on the waves in the tests referenced in this paper.

The main working channel of the Fast Flow Facility is $70 \mathrm{~m}$ long and $4.0 \mathrm{~m}$ wide. In the conducted tests, the water depth at the wave paddle was $2.2 \mathrm{~m}$, decreasing to $0.75 \mathrm{~m}$ at the test section (see Figure 1). Table 1 provides details of the measured test conditions and $U_{m}$. For prototype interpretation a model scale of 1:32 would imply a water depth of 24 $\mathrm{m}$ and test conditions covering a range of $H_{s}=5.4$ to $9.9 \mathrm{~m}, T_{p}=10.1$ to $14.7 \mathrm{~s}$ and measured $U_{m}=0.90$ to $1.62 \mathrm{~m} / \mathrm{s}$.

The achieved wave conditions at the test section were derived from a spectral analysis of the water level measurements made using twin wire resistance-based wave gauges.

The near bed velocity measurements were conducted with a downward facing Nortek Vectrino II Profiler. The Vectrino II provides three-component velocity observations with $1 \mathrm{~mm}$ bin sizes over a 30 $\mathrm{mm}$ range with an output rate of up to $100 \mathrm{~Hz}$. In the present study, a $50 \mathrm{~Hz}$ collection frequency was used. The instrument was set to measure the near bed velocity from 30 to $60 \mathrm{~mm}$ above the concrete flume bed.

Standard deviation of $\mathrm{u}(t)$ is calculated over the bin range 11-14 1/3 of the way down the profile where the most reliable data is collected. No 'weak spot' data signal problems were encountred.

Table 1. Measured test conditions and near bed wave orbital velocity in the Fast Flow Facility.

\begin{tabular}{llllll}
\hline Test No. & $h$ & $H_{s}$ & $T_{p}$ & $\gamma_{\mathrm{JS}}$ & $U_{m}$ \\
\hline & $\mathrm{m}$ & $\mathrm{m}$ & $\mathrm{s}$ & - & $\mathrm{m} / \mathrm{s}$ \\
\hline 1 & 0.75 & 0.201 & 1.92 & 2.3 & 0.16 \\
2 & 0.75 & 0.233 & 1.92 & 3.2 & 0.20 \\
3 & 0.75 & 0.254 & 2.08 & 2.7 & 0.23 \\
4 & 0.75 & 0.310 & 2.38 & 2.3 & 0.29 \\
\hline
\end{tabular}

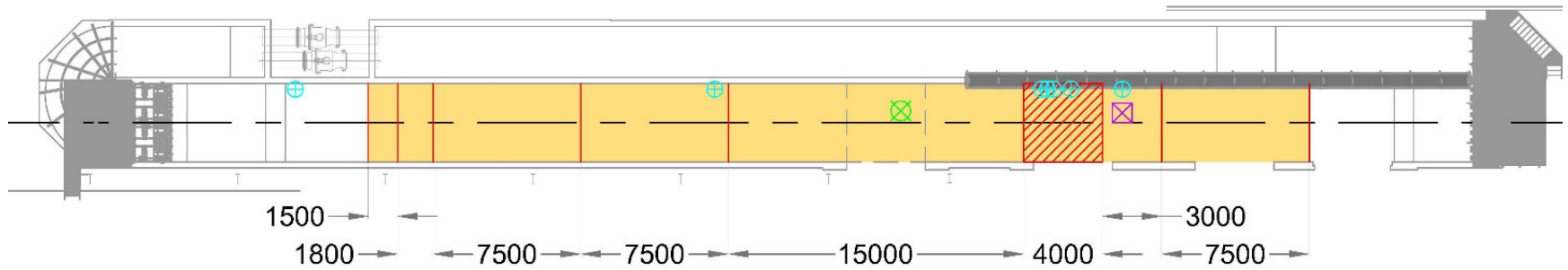

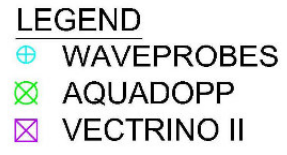

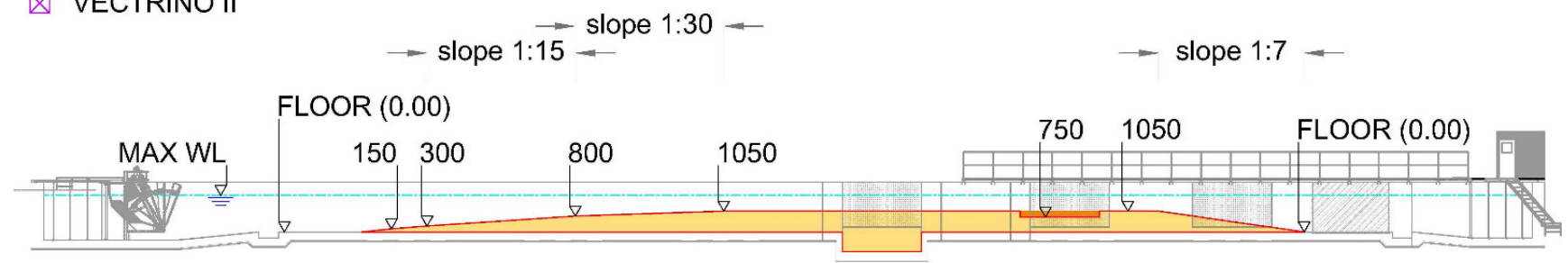

Figure 1. Fast Flow Facility working channel longitudinal section showing build up test section. Dimensions in mm.

\section{PARAMETRIC EXPRESSION FOR NEAR BED WAVE ORBITAL VELOCITY}

In analogy to the linear wave theory of wave orbital motion, a hyperbolic expression of the near bed wave orbital velocity for irregular waves, $U_{m}$, is considered as:

$U_{m}=\frac{\pi H_{r m s} s}{T_{m-1}} \frac{1}{\sinh \left(k_{m-1} h\right)}$ where $H_{r m s}$ is the root-mean-square wave height, $T_{m-1}$ is the spectral wave period defined by $-1^{\text {st }}$ and $0^{\text {th }}$ moment of the wave spectrum and $k_{m-1}$ is the wave number based on $T_{m-l}$ and water depth $h$ :

$H_{r m s}=\frac{H_{s}}{\sqrt{2}}$

where $H_{s}$ is the significant wave height, defined as $H_{m 0}$ from the $0^{\text {th }}$ moment of the wave spectrum. 
$k_{m-l}$ can be calculated from:

$k_{m-1}=\frac{2 \pi}{L_{m-1}}$

where $L_{m-1}$ is the wave length, which can be calculated from the dispersion relation:

$L_{m-1}=L_{o, m-1} \tanh \left(k_{m-1} h\right)$

$L_{o, m-1}$ is the deep water wave length:

$L_{o, m-1}=\frac{g}{2 \pi} T_{m-1}^{2}$

In CIRIA (2007) and De Vos et al. (2012) it is found that, for a JONSWAP wave spectrum, the $T_{m-1}$ wave period can with good approximation be taken as:

$T_{m-1}=\frac{T_{p}}{1.1}$

where $T_{p}$ is the peak wave period.

The exponential expression for $U_{m}$, derived by Soulsby (2006), is:

$U_{m}=\frac{H_{S}}{2 \sqrt{2}} \sqrt{\frac{g}{h}} \exp \left\{-\left[\frac{3.65}{T_{z}} \sqrt{\frac{h}{g}}\right]^{2.1}\right\}$

Where $T_{z}$ is the zero crossing wave period. $T_{z}$ can, as an approximation, be taken as:

$T_{z}=\frac{T_{p}}{1.3}$

In Figure 2, normalized $U_{m}$ is plotted against water depth normalized by the peak deep water wave length, $\mathrm{h} / \mathrm{L}_{\mathrm{o}, \mathrm{p}}$.

The figure compares the hyperbolic (9) and exponential (15) expressions of $U_{m}$ to numerical calculations based on three JONSWAP spectrum's with $\gamma_{\mathrm{JS}}=1,3$ and 5 .

To illustrate engineering application, $U_{m}$ is in (9) and (15) calculated using (14) and (16) for $T_{m-1}$ and $T_{z}$ respectively.

The comparison is carried out from $\mathrm{h} / \mathrm{L}_{\mathrm{o}, \mathrm{p}}=0.05$ to 0.5 . For $h / \mathrm{L}_{\mathrm{o}, \mathrm{p}}<0.1$, depth limited wave breaking gradually sets in. For $\mathrm{h} / \mathrm{L}_{\mathrm{o}, \mathrm{p}}>0.5$, only limited wave action reaches the seabed.

From Figure 2, some impact of wave spectrum is observed, but noted to be within the experimental scatter of measured $U_{m}$.

It is seen that the Soulsby expression provides perfect match to the numerical calculation with JONSWAP peak enhancement factor $\gamma_{\mathrm{JS}}=3$. The hyperbolic expression captures the overall trend, but with less accuracy, particularly at both deeper and very shallow water depths. The Soulsby exponential expression is therefore recommended over the hyperbolic expression.

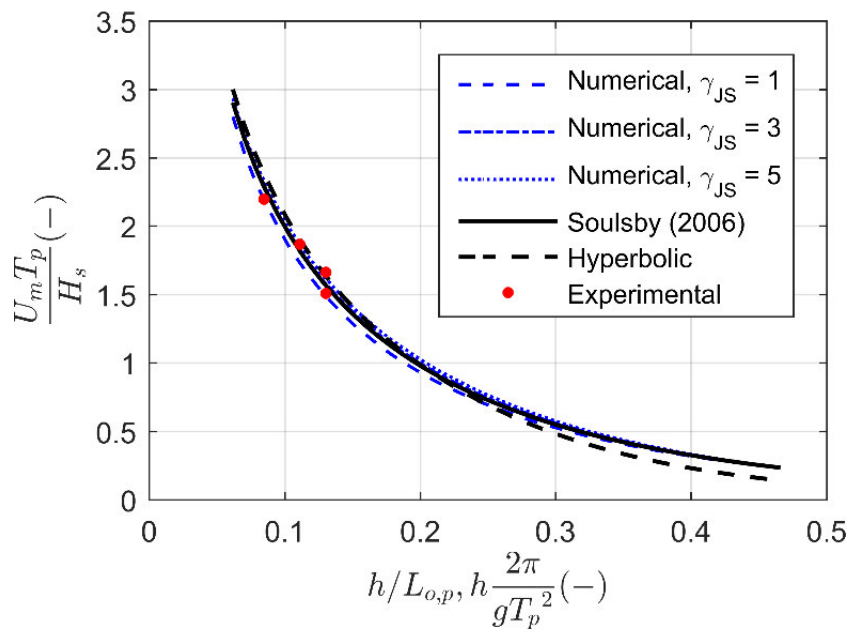

Figure 2. Normalized near bed orbital velocity, $U_{m}{ }^{*}$. Parametric and experimental values verses numerical calculations.

\section{COMPOSITE EXPRESSION FOR WAVE FRICTION FACTOR}

The wave friction factor, $f_{w}$, is defined for regular waves from the relation between the maximum wave bed shear stress, $\tau_{o}$, and the maximum near bed wave orbital velocity (3).

The wave friction factor has been found to depend on the wave stroke to bed roughness ratio:

$f_{w}=f\left(\frac{A}{k_{s}}\right)$

Where $A$ is amplitude of the near bed orbital wave particle motion and $k_{s}$ is Nikuradse's equivalent grain roughness. From Fredsøe and Deigaard (1992) the grain roughness is taken as:

$k_{s}=2.5 D_{50}$

A large number of expressions for the wave friction factor have been suggested in the literature. It can be observed that different expressions provide a good fit within the $A / k_{s}$ range from which they have been determined, but that no single expression provides an acceptable fit within all ranges of $A / k_{s}$.

Dixen et al. (2008) conducted tests for determination of $f_{w}$ for low $A / k_{s}$ values, corresponding to armourstone scour protection rock material. The Dixen et al. (2008) paper includes a figure with experimental data obtained from a large number of studies over the last 70 years. This data is reproduced in Figure 3 together with the Dixen et al. (2008) data.

An important finding by Simons et al. (2000), confirmed in Dixen et al. (2008), is that the friction factor does not approach the constant value of 0.3 for low $A / k_{s}$ values suggested by Bagnold (1946) and incorporated into 'The Rock Manual' (CIRIA, CUR and CEFMET 2007) referencing Soulsby (1997).

The wave friction factor expression referenced in DNV OS-J101 (2014) and Fredsøe and Deigaard 
(1992) fit well to experiments representing sand and very rough bed surfaces, but has a central region of medium bed roughness where the Soulsby (1997) expression appears to better represent the experimental data.

A continuous expression for the wave friction factor is proposed. The expression combines the existing expression of Dixen et al. (2008): (19a), Soulsby (1997): (19b) and Fredsøe and Deigaard (1992): (19c):

$$
\begin{aligned}
& f_{w}= \\
& \left\{\begin{array}{cc}
0.32\left(\frac{A}{k_{s}}\right)^{-0.8} & 0.2<\left(\frac{A}{k_{s}}\right)<2.92 \\
0.237\left(\frac{A}{k_{S}}\right)^{-0.52} & 2.92 \leq\left(\frac{A}{k_{S}}\right)<727 \\
0.04\left(\frac{A}{k_{s}}\right)^{-0.25} & \left(\frac{A}{k_{s}}\right) \geq 727
\end{array}\right.
\end{aligned}
$$

The proposed composite wave friction factor expression is plotted in Figure 3 with experimental data.

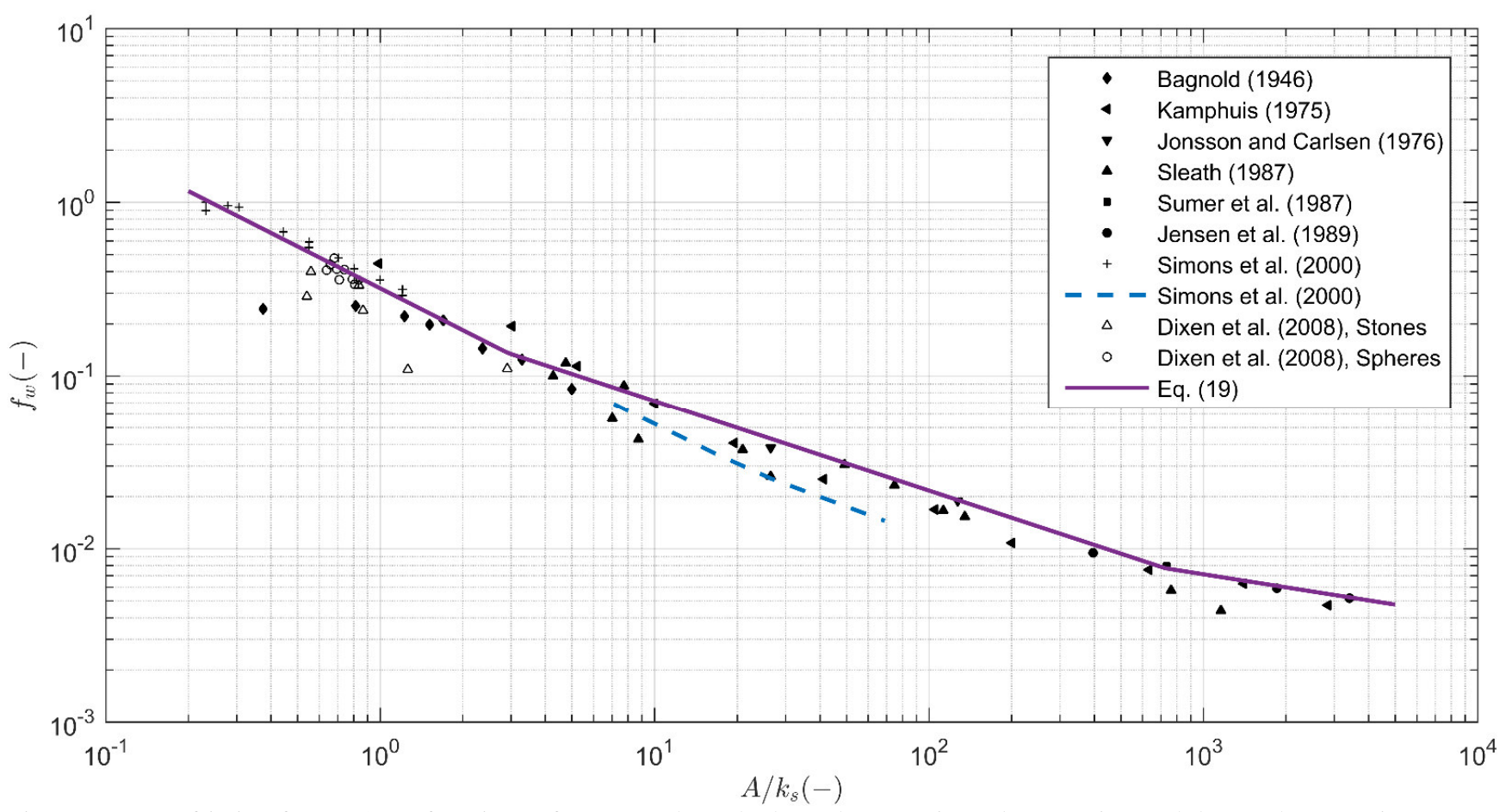

Figure 3. Wave friction factor, $f_{w}$, as functions of wave stroke to bed roughness ratio, $A / k_{s}$. Experimental data and composite expression

\section{PARAMETRIC METHOD FOR CALCULATION OF SHIELDS PARAMETER AND NEAR BED VELOCITY}

The Shields parameter for current in combination with an irregular seasate is calculated by (1) in which $\tau_{\max }$ is derived by combining the current and wave bed shear stresses $\tau_{c}$ and $\tau_{w}$ using the Soulsby (1997) approach. For co-aligned wave and current $\tau_{\max }$ is calculated from:

$\tau_{\max }=\tau_{m}+\tau_{w}$

in which $\tau_{m}$ is the mean bed shear stress $\tau_{m}>\tau_{c} . \tau_{m}$ is basically the current bed shear stress increased due to the presence of waves:

$\tau_{m}=\tau_{c}\left[1+1.2\left(\frac{\tau_{w}}{\tau_{c}+\tau_{w}}\right)^{3.2}\right]$
The current only bed shear stress is calculated from:

$\tau_{c}=\rho_{w} U_{f}^{2}$

where $U_{f}$ is the friction velocity. Assuming a logarithmic velocity profile, the friction velocity can be calculated from the depth averaged current velocity, $U_{c}$, water depth, $h$, and grain roughness, $k_{s}$ :

$U_{f}=\frac{U_{c}}{6.0+2.5 \ln \left(h / k_{s}\right)}$

The wave friction factor (19) is used in (4) for the calculation of the wave bed shear stress $\tau_{w}$.

The wave friction factor is a function of wave stroke to bed roughness ratio, $A / k_{s}$. In regular waves the near bed wave particle amplitude, $A_{o}$, is calculated from:

$A_{o}=\frac{U_{o} \cdot T}{2 \pi}$

In irregular waves, the near bed wave particle amplitude, $A$, is taken as: 
$A=\frac{U_{m} \cdot T_{p}}{2 \pi}$

This expression (25) is derived through the Keulegan-Carpenter number for irregular waves applying $U_{m}$ and $T_{p}$ as proposed by Sumer and Fredsøe (2001):

$K C=\frac{U_{m} T_{p}}{D}=2 \pi \frac{A}{D}$

\section{ENGINEERING EXAMPLE OF APPLICATION}

The parametric approach for the calculation of the Shields parameter is exemplified in Table 2. The table lists the Shields parameters and associated properties for two combined wave/current seastates with seabeds ranging from marine sand, over a coarse and light graded rock typically applied in scour protection design.

While the Soulsby (15) and the hyperbolic expression (9) provides similar results, the Soulsby expression is recommended over the hyperbolic expression as discussed in section 4 .

Table 2. Engineering example of Shields parameter calculation and associated parameters using the Soulsby exponential expression (14) and the hyperbolic expression (8). The example applies salt water density $1026 \mathrm{~kg} / \mathrm{m}^{3}$ and sand/rock particle density 2650 $\mathrm{kg} / \mathrm{m}^{3}$.

\begin{tabular}{llllllllllllll}
\hline$D_{50}$ & $h$ & & & & & \multicolumn{9}{c}{$U_{c}$} & $H_{s}$ & $T_{p}$ & $\theta_{\text {current }}$ & \multicolumn{3}{c}{$U_{m}$} & $a / k_{s}$ & $f_{w}$ & $\theta_{\text {current }+ \text { wave }}$ & $U_{m}$ & $a / k_{s}$ & $f_{w}$ & $\theta_{\text {current }+ \text { wave }}$ \\
\hline $\mathrm{mm}$ & $\mathrm{m}$ & $\mathrm{m} / \mathrm{s}$ & $\mathrm{m}$ & $\mathrm{s}$ & - & $\mathrm{m} / \mathrm{s}$ & - & - & - & $\mathrm{m} / \mathrm{s}$ & - & - \\
\hline 0.2 & 25 & 1.0 & 9.0 & 12.0 & 0.295 & 1.36 & 5204 & 0.0047 & 1.89 & 1.42 & 5439 & 0.0047 & 2.02 \\
63 & 25 & 1.0 & 9.0 & 12.0 & 0.0029 & 1.36 & 16.5 & 0.055 & 0.058 & 1.42 & 17.3 & 0.054 & 0.062 \\
258 & 25 & 1.0 & 9.0 & 12.0 & 0.0011 & 1.36 & 4.0 & 0.115 & 0.029 & 1.42 & 4.2 & 0.112 & 0.031 \\
\hline 0.2 & 25 & 0.6 & 4.0 & 8.0 & 0.106 & 0.36 & 925 & 0.0073 & 0.28 & 0.35 & 879 & 0.0073 & 0.27 \\
63 & 25 & 0.6 & 4.0 & 8.0 & 0.0011 & 0.36 & 2.9 & 0.135 & 0.011 & 0.35 & 2.8 & 0.141 & 0.011 \\
258 & 25 & 0.6 & 4.0 & 8.0 & 0.0004 & 0.36 & 0.7 & 0.418 & 0.008 & 0.35 & 0.7 & 0.435 & 0.007 \\
\hline
\end{tabular}

\section{CONCLUSION}

A methodology for the calculation of the Shields parameter under currents and irregular waves has been presented. The methodology combines wave and current bed shear stresses using the Soulsby (1997) approach.

A hyperbolic expression for the near bed wave orbital velocity, $U_{m}$, has been considered and compared to the Soulsby (2006) exponential expression and validated through numerical calculations and physical modelling tests. The Soulsby expression provides an overall better fit in the validation and is therefore recommended for use over the hyperbolic expression.

Apart from representing the flow regime of an irregular seastate, $U_{m}$ is used for determination of the wave bed shear stress, $\tau_{w}$ through the wave friction factor, $f_{w}$.

From literature study, a composite and continuous expression for the wave friction factor has been proposed by combining existing expressions in their areas of best fit to experimental data.

\section{REFERENCES}

Bagnold, R.A., 1946. Motion of waves in shallow water. Interaction between waves and sand bottoms. Proc. Roy. Soc. Ser. A 187, 1-15.

CIRIA, CUR, CETMEF 2007. The Rock Manual. The use of rock in hydraulic engineering (2nd edition). C683, London: CIRIA.

De Vos, L., De Rouck, J., Troch, P. and Frigaard, P. 2012. Empirical design of scour protection around monopile foundations. Part 2, Coastal Engineering 60: 286-298.

Dixen, M., Hatipoglu, F., Sumer, B.M. and Fredsøe, J. 2008. Wave boundary layer over a stone-covered bed. Coastal Engineering 55: 1-20.

DNV OS-J101 2014. Design of offshore wind turbine structures. Det Norske Veritias A/S.

Jensen, B.L., Sumer, B.M., Fredsøe, J., 1989. Turbulent oscillatory boundary layers at high Reynolds numbers. J. Fluid Mechanics 206, 265-297.

Fredsøe, J. and Deigaard, R. 1992. Mechanics of coastal sediment transport. Advanced series on ocean engineering Volume 3. World scientific, Singapore.

Jonsson, I.G., 1976. Discussion of "Friction factor under oscillatory waves" by J.W. Kamphuis. J.Waterw., Port, Coast., Ocean Div. ASCE 102 (WW1): 108-109.

Nielsen, A.W, Probst, T., Petersen, T.U. and Sumer, B.M. 2015. Sinking of armour layer around a vertical cylinder exposed to waves and current. Coastal Engineering 100: 58-66.

Petersen, T.U., Sumer, B.M, Fredsøe, J. and Raaijmakers, T.C and Schouten, J 2015. Edge scour at scour protections around piles in the marine environment - Laboratory and field investigation, Coastal Engineering 106: 42-72. 
Simons, R., Myrhaug, D., Thais, L., Chapalain, G., Holmedal, L.-E., MacIver, R., 2000. Bed friction in combined wavecurrent flows. Coastal Engineering Conference, ASCE, July 16-21, 2000, Sydney, Australia. Proceedings, 1: 216-226.

Sleath, J.F.A., 1987. Turbulent oscillatory flow over rough beds. J. Fluid Mechanics 182: 360-409.

Soulsby,R.L. 1997. Dynamics of marine sands: a manual for practical applications. London: Thomas Telford.

Soulsby, R.L 2006. Simplified calculation of wave orbital velocities. Report TR 155, Release 1.0, HR Wallingford.

Sumer, B.M. and Fredsøe, J. 2001. Scour around a pile in combined waves and current. J. Hydraulic Engineering 127(5): 403-411.

Whitehouse R., Sutherland J., Powell K., Harris J., 2014. Fast flow facility for sediment and morphology testing. Proceedings of Application of Physical Modelling to Port and Coastal Protection, Coastlab'14, Varna, Bulgaria. ISBN 978-619-90271-2-7. 